\title{
A Psicologia a caminho do novo século: identidade profissional e compromisso social $^{l}$
}

\author{
Ana Mercês Bahia Bock \\ Pontifícia Universidade Católica de São Paulo
}

Resumo

O tema "A Psicologia a caminho do novo século: identidade profissional e compromisso social" foi desenvolvido aqui a partir de três aspectos: um pequeno resgate histórico sobre o vínculo da Psicologia com a sociedade brasileira, buscando caracterizar sua relação com esta sociedade; em seguida, desenvolver a perspectiva da profissão comprometida com a realidade social, apresentando alguns critérios para se julgar o compromisso social de práticas e saberes da Psicologia, além da defesa de que a Psicologia, como saber e fazer, se desenvolva sempre vinculada à sociedade que a acolhe; e para finalizar, trazer a questão da identidade profissional do psicólogo, partindo do princípio de que identidade deve ser sempre vista como metamorfose e como movimento permanente de transformação. $\mathrm{O}$ texto pretende ser uma defesa de uma identidade para os psicólogos que seja movimento e transformação, porque é reflexo do vínculo que a Psicologia deve manter com a sociedade, que está sempre em movimento, vínculo este de compromisso com as necessidades e demandas da maioria da população brasileira.

Palavras-chave:

Psicologia, profissão, compromisso social, identidade profissional 
Key-words: Psychology, profession, social commitment, professional identity

\begin{abstract}
Psychology towards the new century: professional identity and social commitment

The theme "Psychology towards the new century: professional identity and social commitment" was elaborated here from three foundations: 1. a short historical recovery of the links between Psychology and Brazilian society, aiming at the portrayal of its relationship with that society; 2 . the development of a perspective of the profession committed to the social reality, including the presentation of criteria to evaluate the social engagement of practices and understandings of Psychology and the argument that Psychology, as knowledge and doings, should always act in dependence to the society that hosts it; 3 . the prompting of the question of psychologist's professional identity, from the standpoint that identity should always be seen as metamorphosis and a permanent movement of transformation. The text intends to be a defense of an identity for psychologists that implies movement and transformation because it is consequence of the linkage Psychology should entertain with society, which is always moving, a linkage of commitment to the needs and demands of the majority of the Brazilian population.
\end{abstract}

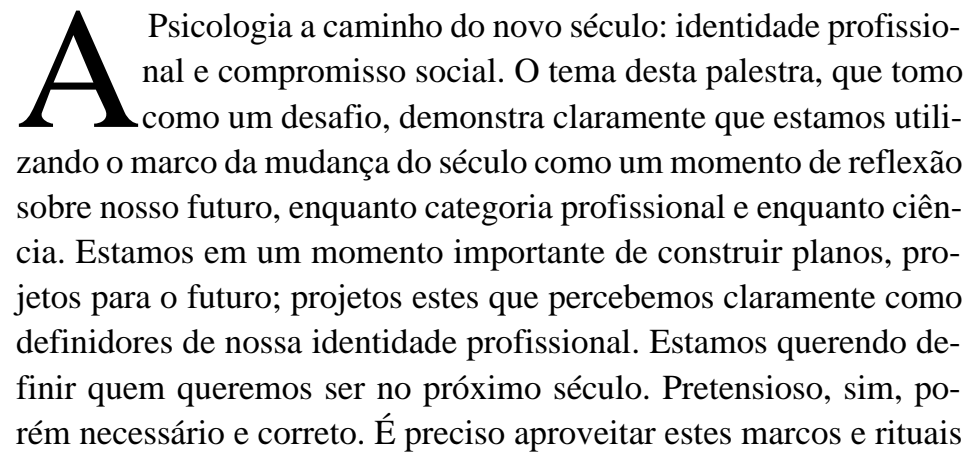


que a nossa cultura nos oferece para refletir sobre nossa atuação como profissionais. Na verdade, há apenas uma aparência de que estamos pensando apenas o futuro. Não; estamos pensando também o presente, o amanhã de nossa profissão.

Quem queremos ser? Que cara queremos dar à nossa profissão? Que inserção social queremos que ela tenha? Que vínculo queremos ter com a sociedade que abriga e recebe nosso trabalho? Que finalidade queremos imprimir às nossas ações? Estas são questões que, a meu ver, estão embutidas no tema. Ou melhor, no desafio desta palestra.

Devo confessar, de início, que eu gosto deste desafio. Gosto de poder pensar que participo da definição do futuro de minha profissão. Gosto de poder pensar que o futuro não está pronto e que me cabe participar de sua construção. Isto, na verdade, me encanta. Farei, portanto, esta reflexão com paixão; podem estar certos.

Para começar, gosto de estruturar minha reflexão para que todos possam acompanhar o caminho do meu pensamento e, quem sabe, chegarmos juntos no final. Isto é também um ponto crucial, pois projeto de futuro de uma profissão ninguém faz sozinho. Teremos de enfrentar este outro desafio: construir o futuro juntos.

Pretendo, inicialmente, caracterizar o vínculo que nossa profissão tem tido com a sociedade para, em seguida, refletir sobre o apelo que está sendo feito a ela, hoje. A que perguntas tem respondido e que respostas nossa profissão tem dado à sociedade brasileira? Depois, discutir a perspectiva de uma profissão comprometida com a realidade social, para finalizar com a questão da identidade profissional. Bem, vamos ao trabalho!

\section{A Psicologia e a sociedade: um pequeno resgate}

Se voltarmos um pouco mais no tempo, para "começar do começo", vamos encontrar no Brasil Colonial, de acordo com os estudos de Mitsuko Antunes (1999), estudos sobre fenômenos psicológicos, principalmente em obras de outras áreas do saber (tais como Teologia, Moral, Pedagogia, Política e Arquitetura) escritos por autores de formação jesuítica, que tinham claramente a finalidade de contri- 
buir para o controle dos indígenas. São estudos sobre emoção, sentidos, auto-conhecimento, adaptação ambiental, diferenças raciais e outros temas relacionados diretamente à questão do controle político da população colonial.

Com a vinda da Corte Portuguesa para o Rio de Janeiro, grandes alterações sociais acontecem em uma cidade que se aglomera sem condições básicas de vida. Doenças infecciosas proliferam e campanhas de higienização da sociedade vão tomar importância e força. É grande o desenvolvimento do saber médico, guiado pelas idéias da higienização e saneamento físico e moral da sociedade. Os conteúdos psicológicos aparecem então nas produções médicas para caracterizar as doenças da moral, presente nas prostitutas, nos pobres e nos loucos. É o período da criação dos grandes hospícios.

Como eliminar problemas que existem na sociedade? Como manter mão-de-obra barata sem os efeitos indesejáveis que ela trazia? As produções científicas caminhavam na direção destas questões e as respostas são permeadas de racismo científico (como a teoria da degenerescência: quanto mais inferior é a raça, mais propenso à degenerescência os indivíduos estão, por isso o índice de alcoolismo e de loucura eram mais altos entre os negros).

Na Primeira República, última década do século XIX, a Psicologia começa a se separar como área. Na primeira metade do século XX, luta-se pela modernização da sociedade brasileira. Havia um enorme interesse em sair da produção agrária e ingressar na modernidade através do crescimento da industrialização. Estávamos lutando por uma nova sociedade que precisava, para poder se desenvolver a contento, de um homem novo. A defesa da educação, da difusão do ensino, das idéias escolanovistas, vão embasar as produções da época. A Psicologia vem, então, dar fundamentos e elementos para o desenvolvimento destas novas idéias educacionais. E a pergunta para a Psicologia se modifica: que conhecimentos científicos são necessários para desenvolver as crianças na direção desta sociedade moderna que queremos?

Noções de diferenciação das pessoas a partir da idéia de capacidades inerentes aos indivíduos vão crescer no seio da Psicologia, que 
produzirá muitos instrumentos capazes de fazer estas diferenciações. As influências americanas tornam-se dominantes na Psicologia brasileira. As testagens psicológicas trazem, também, a enorme possibilidade de respondermos adequadamente ao desafio da modernização: o homem certo no lugar certo.

Do controle do período colonial, para a higienização do início do século XIX, para a diferenciação no século XX.

O início do século XX será marcado por uma credibilidade muito grande na educação. A educação foi vista como a grande responsável pelo desenvolvimento da sociedade. A relação Pedagogia-estudos psicológicos será, então, altamente reforçada. A Psicologia permitia que a Educação fosse pensada a partir de bases científicas. Posteriormente, na década de 30, os ideais escolanovistas vão acentuar esta relação. A Escola Nova, movimento progressista na Pedagogia moderna, trazia uma nova proposta educacional, a partir de uma concepção de infância que abandonava a visão tradicional, em que a criança era possuidora de uma natureza corrompida, necessitando ser "cultivada" para que o mal fosse desenraizado. A criança passava a ser vista como possuidora de uma natureza pura e boa, que precisava ser conhecida em sua profundidade para que o trabalho educacional pudesse contribuir para mantê-la assim, pura, espontânea, livre. Conhecer seu desenvolvimento para poder corrigir seu percurso se tornou tarefa imprescindível.

Além disso, todo poder de diferenciação criado pela Psicologia contribuiu para seu avanço também na área da Psicologia Organizacional ou do Trabalho. Era possível atuar selecionando o homem certo para o lugar certo. Institutos de seleção e orientação vão surgir (como o ISOP, que comemorou há pouco, seus 50 anos).

A institucionalização da Psicologia era evidente. E é importante registrar que, ao lado de toda uma prática e de um conhecimento "diferenciador" e que via o homem de forma muito simplificada, ahistórica, no qual o aspecto social era, na maior parte das vezes, relegado a segundo ou último plano, convivia um conhecimento crítico que concebia o homem e o fenômeno psicológico como indissociáveis do processo de socialização, entendendo o psiquismo 
como manifestação e como instância histórica e social. Helena Antipoff, Manoel Bomfim e Ulisses Pernambucano representam esse setor da Psicologia, que não foi vitorioso na História, mas que registrou suas idéias, permitindo-nos hoje resgatá-los.

Em 1962, a Psicologia foi definitivamente institucionalizada, através da Lei 4119, que regulamentou a profissão no país. Nos anos que se seguem, cursos de Psicologia proliferaram no país, associações profissionais e científicas, campos de trabalho foram surgindo. Enfim, a Psicologia se desenvolvia com vigor.

No final de década de 70, com as grandes greves operárias, a classe média também foi levada às suas organizações. Criou entidades e fortaleceu as já existentes. Nessa época, precisamente em 1979, os psicólogos, inicialmente em São Paulo, mas seguidos pelo Rio de Janeiro, Minas Gerais, Pernambuco, Rio Grande do Sul e, logo depois, Brasília, Ceará, Paraná, ocuparam ou criaram seus Sindicatos. Os Conselhos foram em seguida ocupados por grupos mais progressistas, que queriam a entidade trabalhando para que a Psicologia se tornasse um instrumento a serviço da população brasileira.

A década de 80 trouxe novos desafios aos psicólogos. A pequena, mas significativa, abertura do mercado de trabalho no serviço público de saúde colocou aos psicólogos e às suas entidades desafios muito grandes. Era preciso "reinventar" uma Psicologia que permitisse contribuir e responder às necessidades daquela população, com a qual não estávamos habituados a trabalhar. Esse fato contribuiu para fortalecer nossas entidades. A década de 80 foi, assim, fervilhante para os psicólogos. Os Sindicatos se uniram e criaram a Federação Nacional dos Psicólogos; os Conselhos também se fortaleceram, produzindo material escrito sobre a profissão e organizando Congressos (como os CONPSI, que aconteceram em São Paulo). Psicólogos ingressaram e fortaleceram o movimento da saúde, chegando a colocar na direção desse movimento uma psicóloga (Mônica Valente), além da participação ativa no Movimento da Luta Antimanicomial.

Estava dada a largada para um período em que os psicólogos iriam se perguntar e refletir sobre a relação de seu trabalho e do próprio fenômeno psicológico com a realidade social. A realidade 
social entrava na Psicologia para remexer tudo o que, durante tantos anos, ficou naturalizado e cristalizado. Estas questões vão tomando formas diferentes dentro da Psicologia, até chegarmos ao momento atual, no qual estamos colocando a questão do compromisso social de nossa profissão e de nossa ciência.

Discutir o compromisso social da Psicologia significa, portanto, sermos capazes de avaliar a sua inserção, como ciência e profissão, na sociedade e apontarmos em que direção a Psicologia tem caminhado: para a transformação das condições de vida? Para a manutenção?

Para contribuir para este debate, pretendo responder a duas questões:

1. Por que hoje se coloca esta exigência para a Psicologia, de atuar com compromisso social?

2. Quais os critérios para se afirmar que a intervenção "demonstra compromisso social"?

Por que, hoje, se coloca esta exigência para a Psicologia, enquanto ciência e profissão, de buscar uma produção e uma intervenção que denote "compromisso social"? Dois pontos me parecem importantes para responder a esta questão.

Primeiro, é preciso comentar alguns dados sobre a situação de nosso país, para que possamos caracterizar a necessidade deste tipo de intervenção.

Considerando-se o Produto Interno Bruto (PIB), o Brasil ocupa, hoje, o lugar de $10^{\mathrm{a}}$ economia mundial. Entre 174 nações, o Brasil é a $10^{\text {a }}$ em produção de riqueza.

Mas, se considerarmos, agora, o Índice de Desenvolvimento Humano (IDH), o Brasil tem outra classificação: somos a $79^{\text {a }}$ nação. Somos a $86^{2}$ em educação; temos altos índices nas taxas de mortalidade infantil, em analfabetismo, e baixos nas condições de moradia e saneamento básico, em atendimento à saúde da população... E 15,8\% da população brasileira, ou seja, 26 milhões de pessoas, não têm acesso às condições mínimas de saúde, educação e serviços básicos. Somos, para coroar esse quadro, a nação campeã em concentração de renda. O PIB per capita dos 20\% mais ricos (US\$18.563) é 32 
vezes maior do que o dos $20 \%$ mais pobres (US\$578). Os $20 \%$ mais pobres ficam com apenas $2,5 \%$ da renda, enquanto que os $20 \%$ mais ricos detêm $63,4 \%$ dela.

Estes índices se traduzem em péssimas condições de vida para a maioria de nossa população, que não tem acesso aos serviços básicos de saúde e educação. Temos, de 160 milhões de habitantes, 46 milhões fora da escola, sendo 43 milhões de adultos analfabetos (totais e funcionais) e 3 milhões de crianças entre 7 e 14 anos. Se tomarmos o dado dos que estão na escola, vamos assistir a uma "mortalidade escolar" (termo utilizado aqui para designar a perda de alunos que a escola sofre) impressionante: 38 milhões no ensino fundamental; 5,5 milhões no ensino médio e 2 milhões no ensino superior. Sem distribuição de renda, nenhum outro problema é resolvido e todas as medidas tornam-se paliativas.

Temos um país no qual a média de imposto de renda das instituições financeiras foi, em 1998, de R \$630,00; o total de imposto territorial rural em 1998 foi 250 milhões, em um país que tem a maior área cultivável do planeta (para comparar, o cigarro arrecadou 1 bilhão de reais no mesmo ano!).

E que políticas sociais temos tido em nosso país? Estamos sob os ditames do Banco Mundial e do Fundo Monetário Internacional que, na busca de administrar e controlar os empréstimos feitos por grandes financiadores internacionais aos países em desenvolvimento, vêm interferindo em suas políticas domésticas. São medidas que visam permitir que o Estado vá desinvestindo em setores não-lucrativos, para poder aumentar suas possibilidades de pagamento da dívida externa.

Que país é este? Que situação dramática a que vivemos!

É importante, aqui, fazer uma distinção semântica. Muitos têm dito que vivemos uma situação trágica. Não, não vivemos. Tragédia é um termo que designa acontecimentos que despertam lástima, uma ocorrência funesta, mau fado, infortúnio... Algo que o "destino" nos reservou, porque independe de nossa intervenção. Terremotos, ciclones, tempestades são tragédias. Devemos utilizar nestes casos, como é o caso brasileiro, o termo drama, que também designa acon- 
tecimento terrível, catastrófico, mas que aqui se refere à interferência humana. Temos em nosso país uma situação dramática!

Fechado esse parêntese semântico, volto ao nosso drama. Poderíamos ficar aqui horas descrevendo as características de nossa situação econômica e política e as condições de vida de nosso povo. Mas sabemos que todos aqui a conhecem bem. Queria apenas começar situando a sociedade em que acontece nossa profissão e nossa ciência.

E o que nós, psicólogos, temos com isto?

Nós, profissionais da vida, não podemos deixar de considerar este quadro, porque é dele e nele que podemos caracterizar as necessidades e demandas para nossa profissão. Não podemos mais nos pensar como profissionais que, em consultórios particulares ou escritórios, oferecemos nossos serviços acreditando que estamos tendo alguma contribuição ou interferência para a melhoria das condições de vida. Sei que não tem sido fácil sair destes lugares, pois estamos nos centros urbanos e precisamos trabalhar. Mas não perceber as limitações sociais de nosso trabalho ou mesmo, pior ainda, camuflar isto com justificativas de que sofrimento psíquico é igual para todos (ricos e pobres) é alguma coisa que não se pode mais aceitar. Precisamos reconhecer as limitações de nossa ação profissional, pois isto já é um bom começo.

Bem, recordando nosso trajeto nesta reflexão, estávamos buscando responder por que, hoje, se coloca a exigência do compromisso social. Apresentamos, então, dados sobre as condições de vida em nosso país e pretendemos aqui concluir este primeiro ponto afirmando que, hoje, se coloca essa exigência porque as condições de vida de nosso povo estão se deteriorando; há muita pobreza, muita carência e estas situações têm gerado sofrimento psíquico e nós, psicólogos, já não podemos mais estar de costas para esta realidade. Ela entra pela nossa casa; ela se estampa nos jornais e na televisão; ela nos atinge em nosso trabalho. A realidade já é tão evidente que nos perturba e nos coloca questões.

Mas, para irmos adiante em nossa reflexão, poderíamos nos perguntar: mas o Brasil sempre viveu com dificuldades; as condições de 
vida em nosso país podem estar piores, mas nunca estiveram boas. Por que agora esta exigência?

Porque a Psicologia vem se transformando e vem se aproximando de visões concretas e históricas, abandonando as visões naturalizantes que ainda caracterizam nossa ciência e nossas técnicas.

Vamos explicar melhor isto:

A Psicologia em seu desenvolvimento esteve sempre presa a uma dicotomia entre objetividade e subjetividade; entre interno e externo; entre natural e histórico; objeto e sujeito; razão e emoção; indivíduo e sociedade.

Desde Wundt, temos vivido esse desafio de superar estas dicotomias e nosso desenvolvimento teórico pode ser registrado a partir destas tentativas.

Mantidas estas dicotomias, não temos sido capazes de compreender o homem que não de forma a naturalizar seu desenvolvimento e seu mundo psicológico. Explicando melhor: porque mantemos uma visão dicotômica, temos explicado o movimento do mundo psicológico como um movimento interno, gerado por si mesmo. É a imagem do Barão de Munchhausen que sai do pântano puxando pelos seus próprios cabelos, imagem esta que usei em meu trabalho de doutoramento para simbolizar as idéias que a Psicologia tem construído, que vêem o homem como um ser capaz de, através de seu próprio esforço, se autodeterminar (Bock, 1999).

Esta tradição naturalizante do fenômeno psicológico nos jogou em uma perspectiva de profissão que sempre compreendeu nossa intervenção como curativa, remediativa, terapêutica. Temos nos limitado a ela nestes anos todos de profissão. Não é para menos que temos tido um modelo médico de intervenção.

Mas isto vem mudando. A realidade objetiva, o mundo social e cultural vem invadindo nosso conhecimento e já não podemos mais falar de mundo psicológico sem considerar o mundo social e cultural. Ainda estamos construindo um modelo de relação entre estes mundos, entendendo que estes se influenciam e não que constituem um ao outro. Isto significa que ainda não superamos a dicotomia... mas estamos caminhando. 
A Psicologia tem se aberto para estas novas leituras. Queremos entender o mundo psicológico como um mundo constituído a partir de relações sociais e de formas de produção da sobrevivência. Quero, aqui, explicar melhor, pois penso que este aspecto é fundamental.

A Psicologia, ao pensar o indivíduo descolado de seu mundo social e cultural, viu o desenvolvimento deste ser como produzido pelo seu próprio movimento. Algo dentro de nós nos movimenta. $\mathrm{O}$ mundo social ficou isento. Construímos uma Psicologia que não precisa fazer qualquer referência ao mundo social e cultural para falar do humano. Temos visto isto em pronunciamentos de psicólogos que explicam o que se passa com um indivíduo sem fazer qualquer referência a questões políticas, econômicas e culturais de nossa sociedade. O máximo que avançamos é até o pai e mãe do indivíduo. Nem na família, enquanto instituição social que se estrutura para responder às necessidades da sociedade burguesa e capitalista, chegamos ainda. Mas estamos avançando!

A Psicologia está, então, se abrindo para estas questões e isto coloca o compromisso social como uma possibilidade, como uma exigência, como um critério de qualidade da intervenção.

Penso que outros aspectos existem, mas me dou por satisfeita para responder à primeira questão a que me propus com estes dois elementos: o país exige nosso posicionamento político no exercício da profissão e a Psicologia começa a nos possibilitar este posicionamento com seu avanço na crítica da naturalização de fenômeno psicológico que caracterizou a história de nosso conhecimento.

\section{Psicologia e Compromisso Social: uma tarefa necessária}

Podemos partir, então, para nossa segunda questão: quais os critérios para se afirmar que a intervenção demonstra "compromisso social"?

Não tenho aqui a pretensão de esgotar os critérios possíveis para esta classificação. Mas vou apontar alguns que me parecem importantes.

Primeiro: o trabalho do psicólogo deve apontar para a transformação social, para a mudança das condições de vida da população brasileira. Friso que disse "apontar", porque é a finalidade do traba- 
lho que importa ser caracterizada aqui. Estamos falando do compromisso, portanto de uma perspectiva ética. Assim, vale a intenção. A finalidade do trabalho.

O psicólogo não pode mais ter uma visão estreita de sua intervenção, pensando-a como um trabalho voltado para um indivíduo, como se este vivesse isolado, não tivesse a ver com a realidade social, construindo-a e sendo construído por ela. É preciso ver qualquer intervenção, mesmo que no nível individual, como uma intervenção social e, neste sentido, posicionada. Vamos acabar com a idéia de que mundo psicológico não tem nada a ver com mundo social. Que sofrimento psíquico não tem nada a ver com condições objetivas de vida. Os psicólogos precisam ter clareza de que, ao fazer ou saber Psicologia, estão com sua prática e seu conhecimento interferindo na sociedade. Temos exemplos de como nossos conceitos serviram para acobertar as desigualdades sociais. Diferenças individuais, perspectivas classificatórias, noções abstratas de ser humano e de mundo psicológico nas quais a noção de potencialidades estava dada de forma apriorística à vida, a própria noção de desenvolvimento, permitiram que as condições sociais que facilitam ou impedem o "desenvolvimento" do sujeito ficassem camufladas por detrás de discursos abstratos e ideológicos. $\mathrm{Na}$ área da educação existe um exemplo bem evidente: falamos de fracasso escolar e de dificuldades de aprendizagem nos referindo sempre ao aluno. Como podemos acreditar que uma parte apenas de um processo (a criança) fracasse sozinha? $\mathrm{O}$ processo de ensino-aprendizagem fracassou, não o aluno. Não temos dúvida, hoje, de que a Psicologia contribuiu para ocultar as condições desiguais de vida no decorrer da História.

Precisamos escapar disto e nos engajar politicamente através da finalidade de nossa intervenção. Quero esclarecer que penso que sempre tivemos finalidades para nosso trabalho, mas nunca quisemos colocá-las em debate. Nunca quisemos evidenciá-las. Agora é hora!

Outro critério que podemos utilizar é verificar se a prática escapa do modelo médico de fazer Psicologia. Isto é, se a prática desenvolvida não pensa a realidade e o sujeito a partir da perspectiva da doença. O psicólogo pode e deve, hoje, pensar sua intervenção de 
maneira mais ampla, no sentido da promoção da saúde da comunidade - e isto significa compreender o sujeito como alguém que, ampliando seu conhecimento e sua compreensão sobre a realidade que o cerca, se torna capaz de intervir, transformar, atuar, modificar a realidade. Claro que a doença é uma possibilidade nesta realidade, mas nunca pode ser o eixo para a Psicologia.

Um terceiro critério é o tipo de técnica que se utiliza. Nossas técnicas têm sido construídas e utilizadas com uma determinada camada social, em geral intelectualizada e muito verbal. A população brasileira, na sua maioria, não tem costume e facilidade para trabalhar a partir das técnicas com as quais estamos acostumados. É preciso inovar - e inovar a partir das características da população a ser atendida. Nossa formação tecnicista tem nos ensinado coisas prontas para aplicar. Precisamos nos tornar capazes de criar Psicologia, adaptando nossos saberes à demanda e à realidade que se nos apresenta.

Assumir um compromisso social em nossa profissão é estar voltado para uma intervenção crítica e transformadora de nossas condições de vida. É estar comprometido com a crítica desta realidade a partir da perspectiva de nossa ciência e de nossa profissão. É romper com 500 anos de desigualdade social que caracteriza a história brasileira, rompendo com um saber que oculta esta desigualdade atrás de conceitos e teorias naturalizadoras da realidade social. Assumir compromisso social em nossa prática é acreditar que só se fala do ser humano quando se fala das condições de vida que o determinam. Termos práticas terapêuticas deve significar termos práticas capazes de alterar a realidade social, de denunciar as desigualdades, de contribuir para que se possa cada vez mais compreender a realidade que nos cerca e atuarmos nela para sua transformação no sentido das necessidades da comunidade social. Assumir compromisso social em nossa ciência é buscar estranhar o que hoje já parece familiar; é não aceitar que as coisas são porque são, mas sempre duvidar e buscar novas respostas. Compromisso social é estranhar, é inquietar-se com a realidade e não aceitar as coisas como estão. É buscar saídas. É isto 
que parte de nossa categoria profissional vem fazendo, o que é motivo de orgulho para todos nós.

\section{Movimento e transformação: uma identidade profissional para os psicólogos}

E, para terminar minha reflexão, trago a questão da identidade profissional do psicólogo. Tenho resistido um pouco a discussões sobre a identidade da Psicologia, porque, em geral, essas discussões buscam uma cara para a Psicologia pensando em poder mantê-la depois de encontrada. Quero uma Psicologia que se metamorfoseie o tempo todo, acompanhando as mudanças da realidade social de nosso país. Não podemos querer uma Psicologia que seja a cristalização de uma mesmice de nós mesmos. Se entendermos que a identidade é movimento, é metamorfose, devemos entender que a identidade profissional nunca estará pronta; nunca terá uma definição. Estará sempre acompanhando o movimento da realidade. Na verdade, penso que nos enganamos quando falamos que não temos identidade profissional. Temos sim. Temos uma identidade profissional que reflete a prática importante que temos tido, porém elitista, restrita, pouco diversificada e colada às necessidades e demandas de setores dominantes de nossa sociedade. Uma minoria que, possuindo condições de comprar nossos serviços, foi por muito tempo a única usuária deles. Queremos agora dar a volta por cima e construir uma profissão identificada com as necessidades da maioria da população brasileira, uma maioria que sofre, dadas as condições de vida que possui; uma maioria que luta, dadas as condições de vida que possui. Identificar-se com as necessidades de nosso povo e acompanhar o movimento destas necessidades, sendo capazes de construirmos, sempre e permanentemente, respostas técnicas e científicas. É este o nosso desafio.

Queremos estar em busca permanente, em movimento sempre. Queremos que o movimento seja a nossa identidade e que a inquietação seja nosso lema.

\section{Referências}

Antunes, M. A. M. (1999). A Psicologia no Brasil: leitura histórica sobre sua constituição. São Paulo: Unimarco.

Bock, A. M. B. (1999). Aventuras do Barão de Munchhausen na Psicologia. São Paulo: EDUC. 
Ana Mercês Bahia Bock, doutora em Psicologia Social pela PUCSP, é psicóloga e professora de Psicologia Social e da Educação na PUCSP, diretora da Faculdade de Psicologia (gestões 93/97 e 97/2001), presidente do Conselho Federal de Psicologia (gestões 97/98 e 98/2001). É co-autora do livro Psicologias: uma introdução ao estudo da Psicologia, pela Saraiva, e autora do livro Aventuras do Barão de Munchhausen na Psicologia, pela EDUC/Cortez. Endereço para correspondência: Pontifícia Universidade Católica de São Paulo, Rua Monte Alegre, 984, 05014-901, São Paulo, SP. Email: anabock@zaz.com.br. 